\title{
Portacaval shunt for glycogen storage disease and hyperlipidaemia
}

THOMAS E. STARZL, CHARLES W. PUTNAM, KENDRICK A. PORTER and JOSEPH BENICHOU

Department of Surgery, Denver Veterans Administration Hospital and University of Colorado Medical Center, Denver, Colorado, and Department of Pathology, St Mary's Hospital Medical School, London

Abstract Complete portacaval shunt was used to treat 10 patients with glycogen storage disease. A favourable effect was noted on body growth and a number of metabolic abnormalities. More recently, continuous night feedings with an intermittently placed gastric tube or through a gastrostomy has been shown to be helpful either before or after portacaval shunts. Such alimentation techniques may eliminate the need for shunts in some patients and be of adjuvant benefit in others.

Portacaval shunt was also used for three children who had homozygous Type II hyperlipidaemia. Substantial reductions in serum cholesterol concentration were observed, as well as resorption of xanthomas. Reversal of some cardiovascular lesions has been documented.

The benefits of portacaval shunt in these disorders is probably due to the change in the hormone climate of the liver and the whole organism brought about by diversion of the hormone-rich splanchnic venous blood around the liver.

Earlier during this symposium we described how diversion of hepatotrophic substances around the liver with portacaval shunt influenced liver structure and function in many species, including man, and we discussed the possible mechanisms of these changes in the general context of alterations of the hepatic hormonal milieu (Starzl et al., pp. 111-129). There are many clinical implications of this hepatotrophic concept, as other contributors will enumerate. Here, we shall confine our remarks to portacaval shunt for glycogen storage disease and for Type II hyperlipidaemia. Our present understanding is that the metabolic gains thereby obtained in these diseases are paid for by placing the liver at a specific physiological disadvantage.

\section{GLYCOGEN STORAGE DISEASE}

When portal diversion was first performed for glycogen storage disease almost 

venous blood : to peripheral $\mathrm{i}$ : coincidentally. clear, the cor: ranging than $t$

That first $\mathrm{F}$ almost 14 yea: Riddell et al. died two days Simple portac: our series, of : than five year: years ago (St: palliation of $t$ : had added an parenteral hyf: pre-existing $h=$ lipidaemia. A techniques as $=$ ation (see late: The ages of in Table 1 . $\mathrm{T}$ most commor. glucosidase de

Metabolic eff

After porta: aemia did not night feeding: glucagon in se: in Fig. 1. The (Lockwood et and there wer were much the in all the patis

In spite of: in several of $c$ 
14 years ago (Starzl et al. 1965), the rationale for the procedure was different from what it is today. Then, it was hoped that by short-circuiting splanchnic venous blood around the liver, glucose would be made more readily available to peripheral tissues with relief of hypoglycaemia, and that the liver would be coincidentally deglycogenated. As the content of this symposium has made clear, the consequences of portacaval shunt are far more subtle and wideranging than that simple view suggests.

That first patient who had Type III glycogen storage disease is still alive almost 14 years after portacaval transposition. A patient similarly treated by Riddell et al. (1966) also survived chronically. Because our second patient died two days after portacaval transposition this procedure was abandoned. Simple portacaval shunts were used for all of the eight subsequent patients in our series, of whom seven are alive with follow-ups of eight months to more than five years (mean 60 months). Sporadic further cases summarized four years ago (Starzl et al. 1973a) confirmed the value of portacaval shunt for palliation of these children's condition. By this time, Folkman et al. (1972) had added an important therapeutic dimension by showing how preoperative parenteral hyperalimentation would reduce the operative risk by normalizing pre-existing hepatomegaly, acidosis and other abnormalities, including hyperlipidaemia. A final development has been the refinement of overnight feeding techniques as an alternative to portacaval shunt or as an adjuvant to the operation (see later).

The ages of our 10 patients, types of disease, and symptoms are summarized in Table 1. Type I disease (glucose-6-phosphatase deficiency) has been the most common indication for treatment, with Type III disease (amylo-1,6glucosidase deficiency) being a distant second.

\section{Metabolic effects}

After portal diversion, most of the children who had pre-existing hypoglycaemia did not have relief of this problem or the relief was not complete. Thus, night feedings usually had to be continued. Studies of plasma insulin and glucagon in several of these patients have revealed the interesting pattern shown in Fig. 1. The flat peripheral insulin curves typical of Type I glycogen disease (Lockwood et al. 1969) became significantly elevated after portacaval shunt, and there were smaller increases in glucagon. The glucose tolerance curves were much the same before and after operation. Liver glycogen concentrations in all the patients later biopsied were not changed.

In spite of failure to alter the hepatic glycogen concentration, the liver size in several of our patients and those reported by others underwent a very ob- 


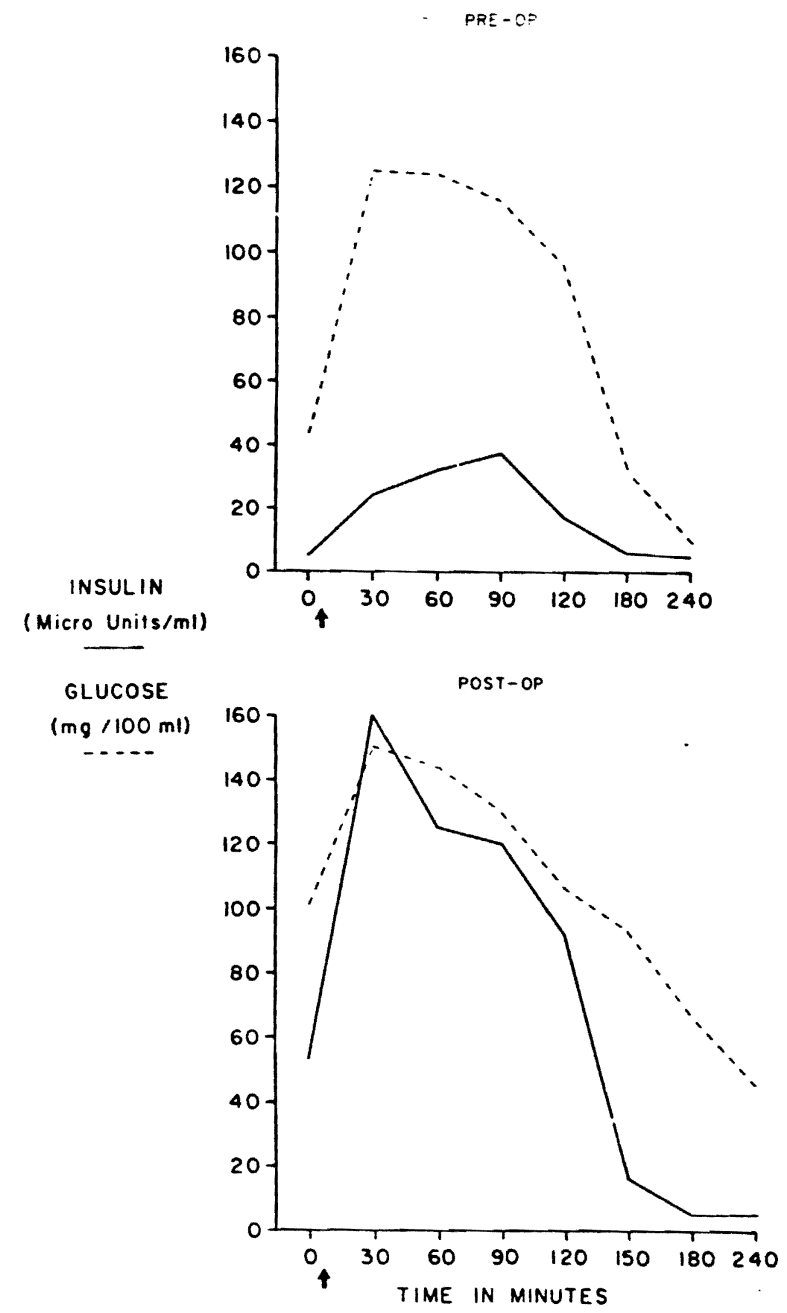

Fig. 1. Plasma insulin and glucose concentrations before and after portacaval shunt in a child (Case 8, Table 1) with Type I glycogen storage disease.

vious reduction as measured with liver scan planimetry. Even if obvious shrinkage did not occur, postoperative biopsies always showed a diminution in individual hepatocyte size similar to that produced in animals by portacaval shunt (Starzl et al. 1973a).

In contrast to the incomplete relief of hypoglycaemia, all components of the hyperlipidaemia which is a characteristic of the Type I disease had profound and permanent relief (Fig. 2) as was first observed by Hermann and Mercer 

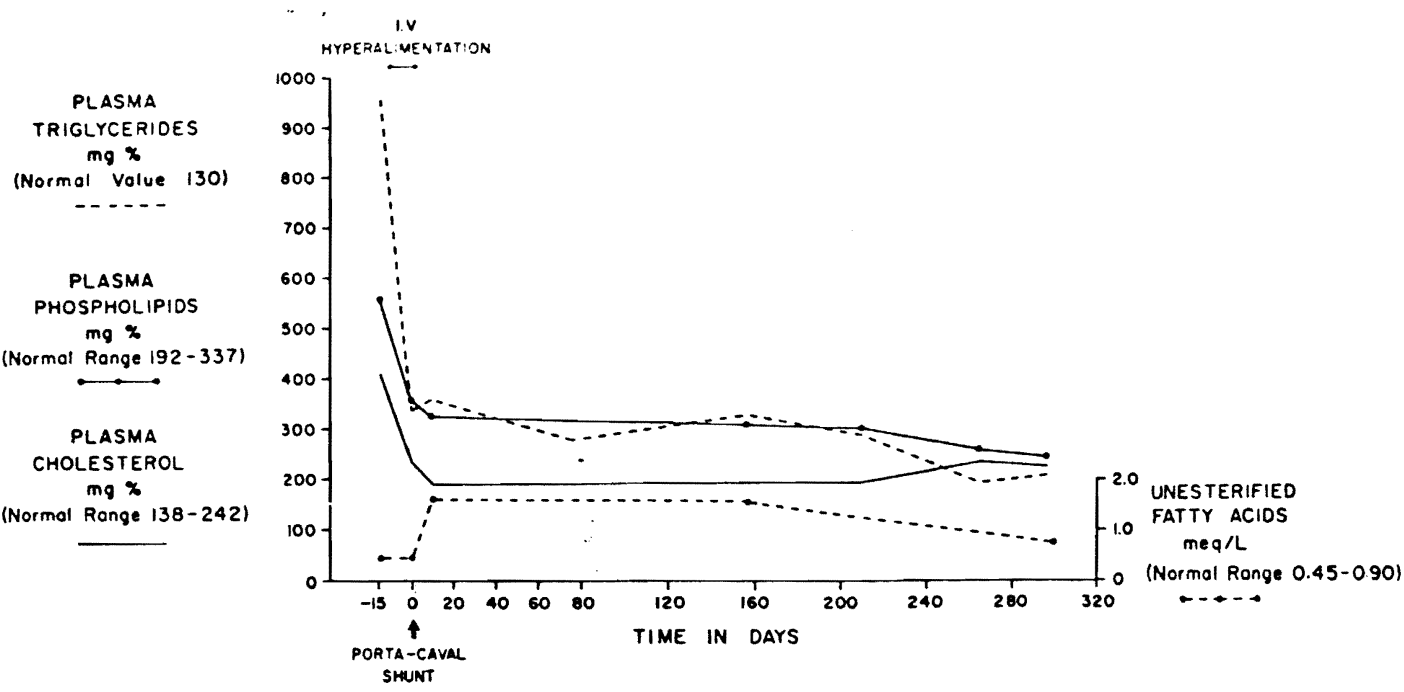

Fig. 2. Effect of parenteral hyperalimentation and end-to-side portacaval shunt on the plasma lipids of Patient 4 whose diagnosis was Type I glycogen storage disease. Note the rapid and relatively complete reversal of all abnormalities. (From Starzl et al. 1973a, by permission of Annals of Surgery.)

TABLE 2

Growth rate and complications after portal diversion for glycogen storage disease

\begin{tabular}{|c|c|c|}
\hline $\begin{array}{l}\text { Case } \\
\text { no. }\end{array}$ & $\begin{array}{l}\text { Growth rate } \\
\text { (cm/month over } 40-120 \text { months) }\end{array}$ & Complications \\
\hline 1 & 0.49 & \\
\hline 2 & Operative death & \\
\hline 3 & 0.50 & Macroadenomatosis \\
\hline 4 & 0.28 & $\begin{array}{l}\text { Died } 43 \text { years after shunt. Primary pulmonary } \\
\text { hypertension, } \mathrm{NH}_{3}=85 \text {, macroadenomatosis }\end{array}$ \\
\hline 5 & 0.53 & $\begin{array}{l}\text { Renal artery stenosis surgically corrected } 32 \\
\text { months after shunt }\end{array}$ \\
\hline 6 & 0.62 & \\
\hline 7 & 0.50 & \\
\hline 8 & 0.49 & \\
\hline 9 & 0.88 & $\begin{array}{l}\text { Renal stone } 2 \text { months after shunt. Mild arterial } \\
\text { hypertension, macroadenomatosis }\end{array}$ \\
\hline 10 & - & \\
\hline Mean: & 0.54 & \\
\hline
\end{tabular}

ents of ofound Mercer
Died 43 years after shunt. Primary pulmonary hypertension, $\mathrm{NH}_{3}=85$, macroadenomatosis Renal artery stenosis surgically corrected 32 hypertension, macroadenomatosis 


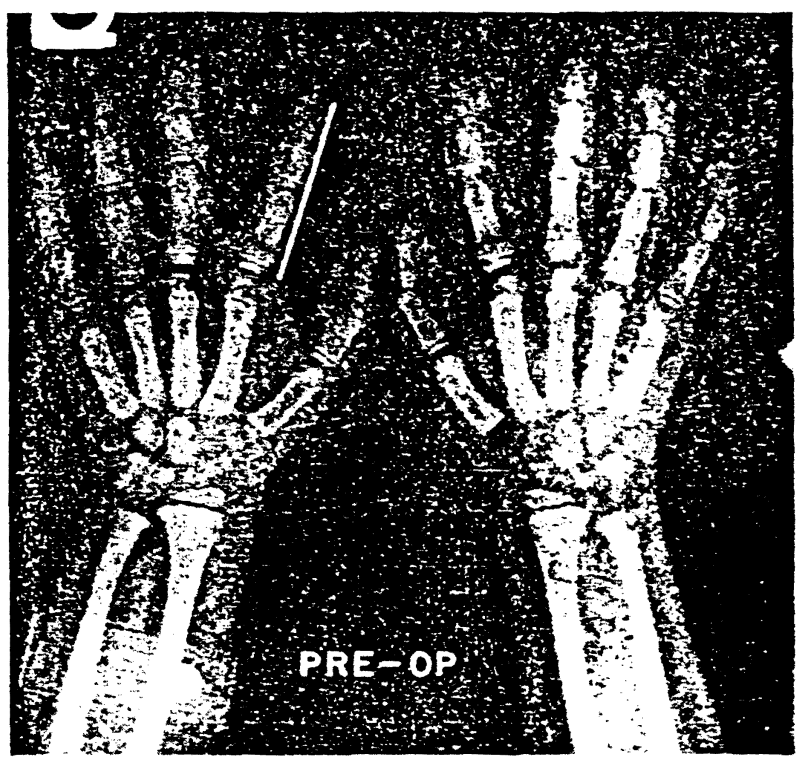

et al. 1 s

abnorm

(Starzl e

Growth

All 1(

Afterwa

occurrec

Quan

(Starzl c of the $w$

after of tion to $t$ bones. spurts I distribu insulin potency

Enceph

Nont

blood : most fi graphic not ac system ventila monia

At : astroc: life w: pulmo intima In ret kind $t$ or ott

The et al. 1973a, by permission of Annals of Surgery.) 
(1969) and confirmed by Folkman et al. (1972) and in our own cases (Starzl et al. 1973a). Correction of other metabolic defects was observed including abnormal bleeding, uric acid elevations, and abnormal calcium metabolism (Starzl et al. 1973a).

\section{Growth}

All 10 of our patients had growth retardation before portacaval shunt. Afterwards, height increases, which in most cases had virtually ceased, have occurred at the rates listed in Table 2, approximately $0.5 \mathrm{~cm}$ per month.

Quantitative measures of growth were obtained with radiographic techniques (Starzl et al. 1973a). An example of the results is shown in Fig. 3. Comparison of the wrist and hands in this seven-year-old stunted child before and $11 \frac{1}{2}$ months after operation showed the phenomenal effects of bone age doubling. In addition to the size change, mineralization occurred and the appearance of new wrist bones. Circulating somatotropin in these patients was normal. The growth spurts may have been at least partially attributable to the increased insulin distribution to the periphery mentioned earlier (see Fig. 1) since, in recent years, insulin has been recognized to be a major growth hormone, comparable in potency to somatotropin.

\section{Encephalopathy and other risks}

None of our patients has developed hepatic encephalopathy. The highest blood ammonia concentration recorded was $84 \mu \mathrm{g} \%$ in a child who died almost five years after portacaval shunt during an attempt at transcaval radiographic visualization of the portacaval anastomosis. This patient (no. 4) had not achieved the full expected growth after operation (Table 2), had mild systemic hypertension, and had unexplained transient bouts of cyanosis, hyperventilation, and unconsciousness. Except for the slightly elevated blood ammonia concentration, liver function was normal.

At autopsy, the liver had macroadenomatosis. Very minor protoplasmic astrocytosis was in the brain. A finding that had not been suspected during life was advanced right ventricular hypertrophy and dilatation. The smaller pulmonary arteries and arterioles had medial muscle hypertrophy, medial and intimal fibrosis, scattered fibrinoid necrosis, and numerous plexiform lesions. In retrospect, the patient died from a cardiopulmonary complication of the kind that has been documented in patients with Type I glycogen storage disease or other liver disease (Levine et al. 1973).

The complication has been termed vasoconstrictive pulmonary hypertension.

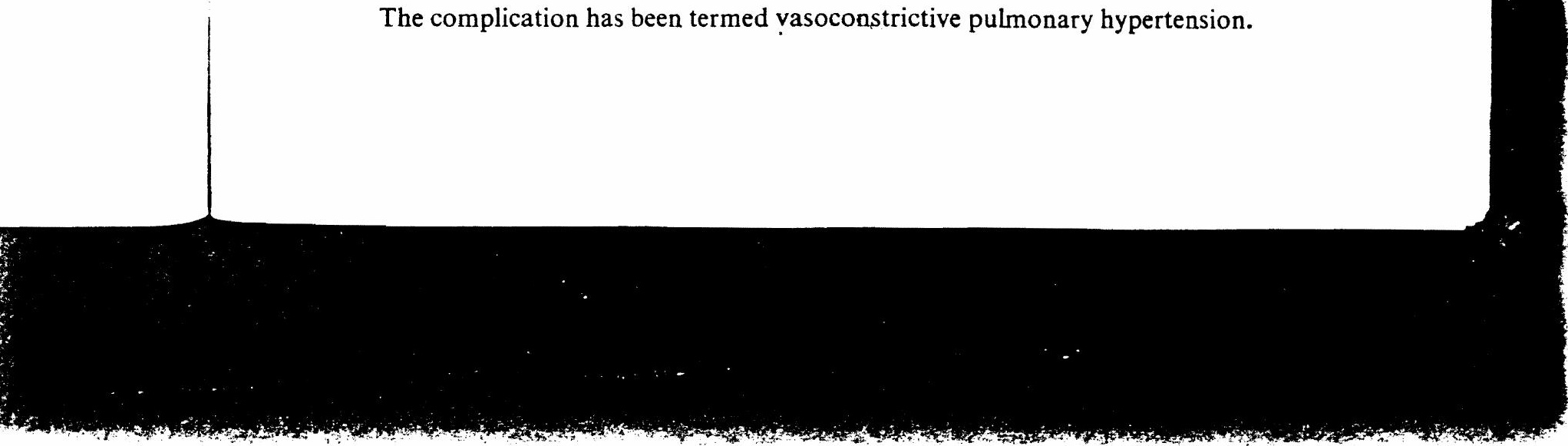


It has been speculated that a humoral vasoconstrictive agent, which normally is completely detoxified by the liver, is responsible for the hypertrophic lesions in the pulmonary vasculature. It is conceivable although unlikely that the development of a renal artery stenosis in patient No. 5 could have been by the same mechanism.

Three of our 10 patients developed the hepatic lesions which have been termed both macroadenomatosis and nodular hyperplasia. Filling defects were noted by liver scan with some waxing and waning of size. This complication is common in patients with Type I glycogen storage disease particularly with advancing age and was recently reported in seven of eight patients who were three to 28 years old (Howell et al. 1976).

\section{The value of night feedings}

The failure of overnight hypoglycaemia to be relieved after portal diversion has already been mentioned. Partly for this reason, the continuous night feeding through a gastrostomy or gastric tube recently advocated by Burr et al. (1974) and Greene et al. (1976) has been a useful if not mandatory adjuvant in some of our cases. Glucose or amino acid mixtures have both been effective.

The night feedings have contributed to or been primarily responsible for the same kinds of growth spurts and relief of metabolic abnormalities (including hyperlipidaemia) as are ameliorated by portacaval shunt. Greene et al. (1976) have shown that systemic plasma insulin levels are more than doubled by such treatment and that glucagon is decreased, leading them to speculate that the hormone changes were responsible for the benefits. Whatever the explanation, this kind of treatment is an alternative to portal diversion as the primary treatment of children with glycogen storage disease, and even after portacaval shunt it has an additional value.

\section{HYPERLIPIDAEMIA}

In the glycogen storage diseases we have been discussing, the livers are always patently abnormal because of the accumulation of glycogen, and often because of fibrosis. By contrast, the liver in homozygous Type II hyperlipoproteinaemia is morphologically normal. The reasons for the elevated serum cholesterol and the low density lipoproteins in this autosomal dominant inherited disorder are by no means understood.

Whatever its cause, the homozygous form of Type II hyperlipoproteinaemia has a shockingly poor prognosis even with attemps at rigid medical therapy. Lipid-rich deposits are laid down in widely separated superficial and deep parts 


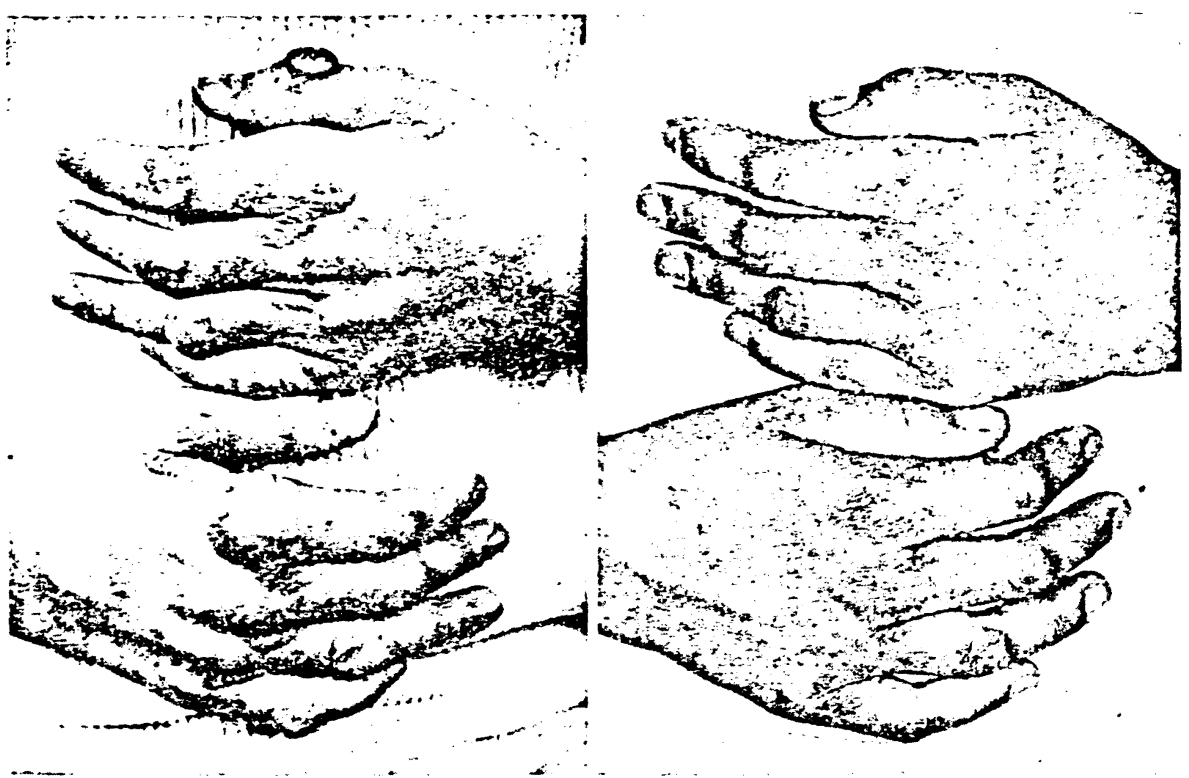

Fig. 4. The hands of Patient 1 of the hyperlipidaemia series two weeks before $(l e f t)$ and 16 months after (right) portacaval shunt.

of the body (Fig. 4), and the same accumulations cause advanced aortic stenosis and coronary artery disease which are responsible for death before the age of 20 years in the usual case.

In an effort to reduce the serum cholesterol and lipoprotein levels, we performed an end-to-side portacaval shunt on March 1, 1973, in an 11-year-old girl with homozygous Type II hyperlipoproteinaemia that was refractory to medical treatment (Starzl et al. 1973b). The patient had suffered a myocardial infarction about two months previously. After surgery, the serum cholesterol values fell from about $800 \mathrm{mg} / 100 \mathrm{ml}$ to levels that were consistently below 400 $\mathrm{mg} / 100 \mathrm{ml}$ (Fig. 5). Unsightly xanthomas began to resorb from visible subcutaneous and tendinous locations. At the same time, attacks of the pre-existing angina pectoris became less frequent and finally stopped. From cardiac catheterization 16 months after the end-to-side portacaval shunt was performed, there was good evidence that aortic stenosis had been reversed with a diminution of the aortic valve gradient from 56 to $10 \mathrm{mmHg}$ (Starzl et al. 1974a). The coronary arteries were also thought to be less diseased than before, although three stenoses were still present. More than $1 \frac{1}{2}$ years later, the girl died suddenly while coming home from school. The autopsy findings led to the conclusion that death was caused by an acute cardiac arrhythmia related to the residual coronary artery disease or to the earlier myocardial infarction (Starzl et al. 1974b). 
Fig. 5. Serum c:

The porta: was grossly $\mathrm{r}$. imen that $\mathrm{u}$ : croscopy, the depletion of : plasmic lipid in all species. Hepatic func: dard liver f $\mathrm{L}$ :

We have $F$. diagnosis ( $\mathrm{C}$ a preoperative while she wa cholesterol le reduction), $c$ tions are at stenosis and : was treated artery by-pas

Ourthird F to $600-650 \mathrm{r}:$ the choleste: xanthomas a The chan gous to the: 


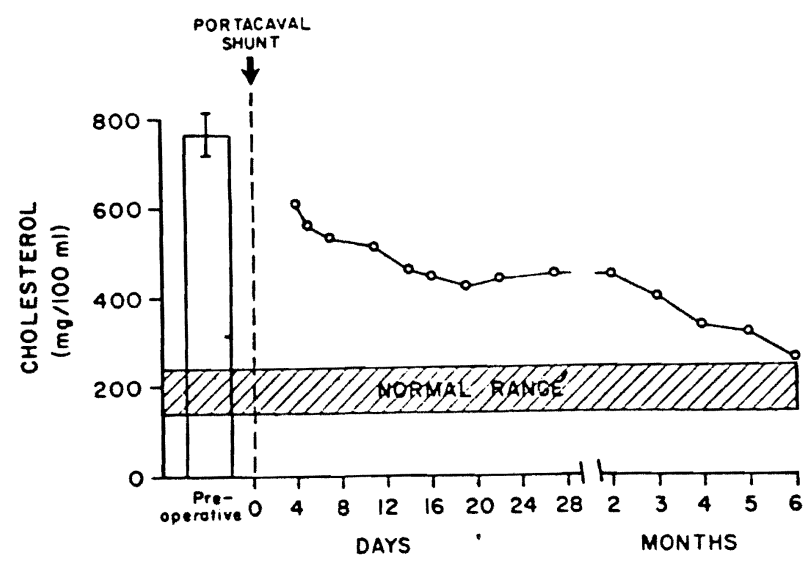

Fig. 5. Serum cholesterol concentrations after port acaval shunt in Patient 1, Table 3.

The portacaval shunt was widely patent. The liver, which weighed $618 \mathrm{~g}$, was grossly normal, and microscopically it was unchanged from the biopsy specimen that was obtained six months postoperatively. On light and electron microscopy, the most prominent findings were shrinkage of the hepatocyte size, depletion of rough endoplasmic reticulum, and the accumulation of intracytoplasmic lipid deposits. These changes are typical of the portaprival condition in all species, as we mentioned earlier (Starzl et al., this volume, pp. 111-129). Hepatic function had not been changed by portacaval shunt as judged by standard liver function tests.

We have performed a portacaval shunt on two more patients with the same diagnosis (Cases 2 and 3, Table 3). Patient 2 is a seven-year-old girl who had preoperative serum cholesterol values that averaged $997 \pm 47$ (s.D.) $\mathrm{mg} / 100 \mathrm{ml}$ while she was on a very low cholesterol diet. Six months after the shunt, the cholesterol level measured in the same laboratory was $600 \mathrm{mg} / 100 \mathrm{ml}$ (a $40 \%$ reduction), despite a relaxation of the diet, and now the cholesterol concentrations are about $450-500 \mathrm{mg} / 100 \mathrm{ml}$ (Table 3 ). This child also had aortic stenosis and angina pectoris. Because of persistence of her cardiac disease, she was treated with aortic and mitral valve replacement plus double coronary artery by-pass two years after portacaval shunt. She is well.

Our third patient has had a reduction in serum cholesterol from $1000 \mathrm{mg} / 100 \mathrm{ml}$ to $600-650 \mathrm{mg} / 100 \mathrm{ml}$ in the 21 months since the operation (Table 3). Although the cholesterol falls were less striking than in our first two patients, visible xanthomas are slowly resorbing and the patient is asymptomatic.

The changes in peripheral insulin content in these patients have been analogous to those in patients treated for glycogen storage disease, but starting with 
- Pre Shunt

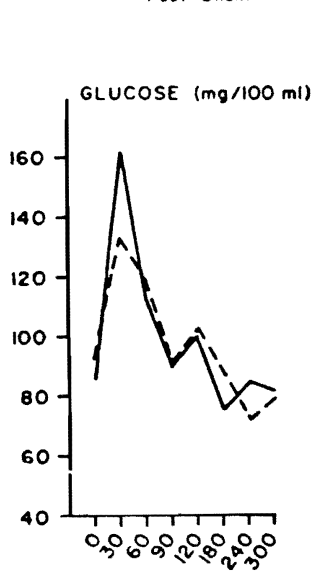

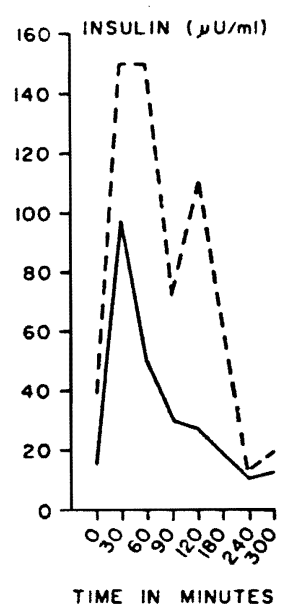

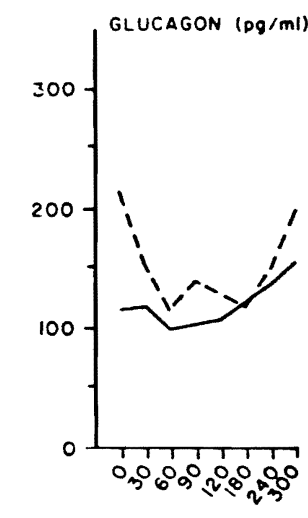

Fig. 6. Systemic venous plasma glucose, insulin and glucagon concentrations in Patient 2 with hyperlipidaemia before and after portacaval shunt. Stimulus was glucose meal.

preoperatively normal values. Postoperatively, systemic venous insulin and glucagon values were both increased, especially the former (Fig. 6).

None of our three patients with hyperlipidaemia has had any signs of hepatic encephalopathy. Nevertheless, this clinical application for hyperlipidaemia, as in the patients with glycogen storage disease, accepts a 'trade-off' of distinctly suboptimal conditions of liver perfusion in return for metabolic improvements that are derived from these suboptimal conditions. Realization of this fact has encouraged us to maintain a conservative and discriminating attitude about the recommendation of portacaval shunt for either kind of inborn error. The freedom from encephalopathy in our cases may be partly due to the fact that we have treated children only.

\section{Other reports}

Shortly after portacaval shunt was first proposed for the treatment of hyperlipidaemia, a plea was made by Ahrens (1974) that all such patients be carefully studied and faithfully reported to a central registry. Knowledge has been acquired in this way about more than 30 patients. More importantly, formal reports have appeared in the literature on nine of these cases in addition to our own three (Krogh \& Wickens 1974; Stein et al. 1975; Russell et al. 1976; Cywes et al. 1976; Farriaux et al. 1976; Weglicki et al. 1977). The degree of

serum choles: our three cas can be expect of angina hav has been asso et al. 1976).

\section{Mechanism 0 .}

Our studie: (Magide et al. (Bilheimer et cholesterol sy dogs bas deni as Ahrens (1C

Our experi, cholesterol si Eaton (1976) may be impor

ACKNOW'LED

This work wa Administration: and by Grants $R$ of the Division.

\section{Reference:}

Ahrens, E. J., . need for a cl

BILHEIMER, D. I cholesterol : hypercholes:

BURR, I. M., O' parison of $t$ portacaval s:

CAREW, T. E., : density and 1 Res. 17,441 .

Chase, H. P. \& pig. Atherosi

CoYle, J. J., Sc The effect of Surgery 80, 
serum cholesterol lowering has been variable from patient to patient, as in our three cases, but it seems established beyond doubt that a significant fall can be expected if the shunt is patent. Resorption of the xanthomas and relief of angina have also been common. Failure to observe an antilipidaemic effect has been associated with thrombosis of the shunt (Cywes et al. 1976; Farriaux et al. 1976).

\section{Mechanism of effect}

Our studies in the dog (Starzl et al. 1975) and investigations in the rat (Magide et al. 1976), pig (Carew et al. 1976; Chase \& Morris 1976), and human (Bilheimer et al. 1975) have shown or suggested that a reduction in hepatic cholesterol synthesis is responsible. Only the report of Coyle et al. (1976) in dogs has denied this. Other factors may contribute to the antilipidaemic effect, as Ahrens (1974) has speculated.

Our experiments have suggested that the main reason for decreased hepatic nt 2 with cholesterol synthesis is deprivation of the liver of insulin (Starzl et al. 1975). Eaton (1976) has recently proposed that the changes in glucagon metabolism may be important.

lin and

hepatic Jaemia, istinctly ements his fact attitude n error. the fact

\section{ACKNOWLEDGEMENTS}

This work was supported by research projects MRIS 8118-01 and 7227-01 from the Veterans Administration; by United States Public Health Service Grants AM-17260 and AM-07772; and by Grants RR-00051 and RR-00069 from the General Clinical Research Centers Program of the Division of Research Resources, National Institutes of Health.

\section{References}

Ahrens, E. J., JR (1974) Homozygous hypercholesteraemia and the portacaval shunt: the need for a concerted attack by surgeons and clinical researchers. Lancet 2, 449-451

Bilheimer, D. W., Goldstein, J. L., Grundy, S. M. \& Brown, M. S. (1975) Reduction in cholesterol and low density lipoprotein synthesis in a patient with homozygous familial hypercholesterolemia. J. Clin. Invest. 56, 1420-1430

Burr, I. M., O’Neill, J. A., Karzou, D. T., Howard, L. J. \& Greene, H. L. (1974) Comparison of the effect of total parenteral nutrition, continuous intragastric feeding and portacaval shunt in a patient with Type I glycogen storage disease. J. Pediat. 85, 792-795

hyperee careas been formal tion to '. 1976; gree of

Carew, T. E., Saik, R. P., Johansen, K. H., Dennis, C. A. \& Steinberg, D. (1976) Low density and high density lipoprotein turnover following portacaval shunt in swine. J. Lipid Res. 17, 441-450

Chase, H. P. \& Morris, T. (1976) Cholesterol metabolism following portacaval shunt in the pig. Atherosclerosis 24, 141-148

Coyle, J. J., Schwartz, M. Z., Marubeio, A. T., Varco, R. L. \& Buchwald, H. (1976) The effect of portacaval shunt on plasma lipids and tissue cholesterol synthesis in the dog. Surgery $80,54-60$
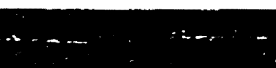
Cy'ues, S., Davies, M. R. Q., Loun, J. H., Berger, G. M. B., Bovnici, F. \& Joffe, H. S. (1976) Portacaval shunt in two patients with homozgous Type II hyperlipoproteinaemia. S. Afr. Med. J. 50, 239-242

EATON, R. P. (1976) Glucagon and lipoprotein. Metabolism 25 (Suppl. 11), 1415.1418

FarriauX, J.-P., Ribet, M., LebecQ, M.-F. \& Lemaitre, L. (1976) Traitement de l'hypercholesterolémie familiale de type II par anastomose portocave. La Nouvelle Presse Médicale 5 (No. 34), 2219-2221

Folkman, J., Philippart, A., Tze, W.-J. \& Crigler, J., JR (1972) Portacaval shunt for glycogen storage disease: value of prolonged intravenous hyperalimentation before surgery. Surgery $72,306-314$

Greene, H. L., Slonim, A. E., O’Neill, J. A., Jr \& Burr, I. M. (1976) Continuous nocturnal intragastric feeding for management of Type I glycogen storage disease. $N$. Engl. J. Med. $294,1125-1129$

HermanN, R. E. \& Mercer, R. D. (1969) Portacaval shunt in the treatment of glycogen storage disease: report of a case. Surgery $65,499-503$

Howell, R. R., Stevenson, R. E., Ben-Menachem, Y., Phyliky, R. L. \& Berry, C. H. (1976) Hepatic adenomata with Type I glycogen storage disease. J. A. M. Med. Assoc. $236,1481-1484$

Krogh, L. \& Wickens, J. T. (1974) Letter. Portacaval shunt for hypercholesterolaemia. S. Afr. Med. J. 48,2302

Levine, O. R., Harris, R. C., Blanc, W. A. \& Wellins, R. B. (1973) Progressive pulmonaty hypertension in children with portal hypertension. J. Pediatr. 83, 964-972

Lockwood, D. H., Merimee, T. J., Edgar, P. J., Greene, M. L., Fujimoto, W. Y., SeegMILleR, J. E. \& Howell, R. R. (1969) Insulin secretion in Type I glycogen storage disease. Diabetes $18,755-58$

Magide, A. A., Press, C. M., Myant, N. B., Mitropoulos, K. A. \& Balasubramaniam, S. (1976) The effect of portacaval anastomosis on plasma lipoprotein metabolism in rats. Biochim. Biophys. Acta 441, 302-307

Riddell, A. G., Davies, R. P. \& Clark, A. D. (1966) Portacaval transposition in the treatment of glycogen storage disease. Lancet 2, 1146-1148

Russell, D., Heimann, K. W., Levin, S. E., Mendelsohn, D., Mega de Andrade, A., Lieberthal, S., Mieny, C., Dinner, M., Joffe, B. I. \& Seftel, H. C. (1976) Portacaval shunt for homozygous hypercholesterolaemia. Lancet 2, 1205

Starzl, T. E., Marchioro, T. L., Sexton, A. W., Illingworth, B., Waddell, W. R., FARIS, T. D. \& HermanN, T. J. (1S65) The effect of portacaval transposition on carbohydrate metabolism: experimental and clinical observations. Surgery 57, 687-697

Starzl, T. E., Putnam, C. W., Porter, K. A., Halgrimson, C. G., Corman, J., Brown, B. I., Gotuln, R. W., Rodgerson, D. O. \& Greene, H. I.. (1973a) Portal diversion for the treatment of glycogen storage disease in humans. Ann. Surg. 178, 525-539

Starzl, T. E., Putnam, C. W., Chase, H. P. \& Porter, K. A. (1973b) Portacaval shunt in hyperlipoproteinaemia. Lancet 2, 940-944

Starzl, T. E., Chase, H. P., Putnam, C. W. \& Nora, J. J. (1974a) Follow-up of patient with portacaval shunt for the treatment of hyperlipidemia. Lancet 2, 714-715

Starzl, T. E., Chase, H. P., Putnam, C. W., Nora, J. J., Fennell, R. H., Jr \& Porter, K. A. (1974b) Portacaval shunt in hyperlipidaemia. Lancet 2, 1263

Starzl, T. E., Lee, I. Y., Porter, K. A. \& Putnam, C. W. (1975) The influence of portal blood upon lipid metabolism in normal and diabetic dogs and baboons. Surg. Gynecol. Obstet. 140, 381-396

Starzl, T. E., Porter, K. A., Francavilla, J. A., Benichou, J. \& Putnam, C. W. (1978) A hundred years of the hepatotrophic controversy, this volume, pp. 111-129

Stein, E. A., Mieny, C., Spitz, L., Saaron, I., Pettifor, J., Heimani, K. W., Bersohn, I. \& DinNer, M. (1975) Portacaval shunt in four patients with homozygous hypercholesterolemia. Lancet 1, 832-835
WEGLICK!, W:

N.P. $119^{--}$ $634-640$

\section{Discussior}

Smith-Lair:

tients to a $\leqq$ looked at any to see if it is

Star $=1$ : The question is $n$ mainly due tic to about onecontributory acids (by rem drain of the $c$

Smith-Lains without a shu the synthesis be drained ( $B$ causes.

Starzl: Yes. which the loss synthesis incre loss of cholest

McIntyre: high cholester these patients (LDL). These olism of plasr It seems unne explanation. consequence o presumably b or as bile acid and its accum

Bloom: Wh

Starzl: Por all the lipid $\mathrm{m}$ Leffert: W' 
F. \& JOFFE, H. S. -lipoproteinaemia.

$1415 \cdot 1418$ ement de l'hyper'le Presse .Médicale

iacaval shunt for mentation before tinuous noiturnal N. Engl. J. Med. ment of glycogen \& BERRY, C. H. 1. M. Med. Assoc. cholesterolaemia. - essive pulmonary ro, W. Y., Seegglycogen storage isLBRAMANIAM, S. tabolism in rats.

;ition in the treatje Andrade, A., -1976) Portacaval

VADDELL, W. R., osition on carbo687-697

:MAN, J., Brown, irtal diversion for $-539$

irtacaval shunt in up of patient with A., JR \& PORTER, Huence of portal s. Surg. Gynecol. +M. C. W. (1978) 129

., BERSUHN, I. \& 7ypercholesterol-
Weglicki, W. B., Ganda, O. P., Soeldier, J. S., Murawski, B. J., Cohn, L. H. \& Couch, N. P. (1977) Portacaval diversion for severe hypercholesterolemia. Arch. Surg. 112, 634-640

\section{Discussion}

Smith-Laing: Do you attribute the fall in lipids in the hyperlipidaemic patients to a general decrease in metabolic processes in the liver? Have you looked at any other synthetic process, such as the rate of synthesis of albumin, to see if it is correlated with the fall in lipids?

Starzl: The answer to your first question is yes. The answer to the second question is no, we haven't. I think the fall in cholesterol concentration is mainly due to a decrease in hepatic cholesterol synthesis, which in dogs falls to about one-seventh after a shunt (Starzl et al. 1975). Ahrens (1974) has a contributory (not alternative) explanation: he suggests that the loss of bile acids (by removal of the portal enterohepatic circulation) creates an obligatory drain of the cholesterol pool.

Smith-Laing: Beckelbaum and his colleagues tried complete biliary diversion without a shunt in three patients with homozygous hypercholesterolaemia and the synthesis of cholesterol kept up with any amount of bile acids that could be drained (Beckelbaum et al. 1977), so presumably it is a combination of causes.

Starzl: Yes. Buchwald et al. (1974) also showed, using an ileal by-pass in which the loss of bile acids increased by several-fold, that the rate of cholesterol synthesis increased to match the loss. So the chief mechanism seems to be the loss of cholesterol synthesis.

McIntyre: I don't believe that. There is no convincing evidence that it is high cholesterol synthesis in the liver which increases serum cholesterol in these patients. They have increased amounts of low density lipoproteins (LDL). These are not normally produced in the liver; they result from catabolism of plasma very low density lipoprotein (VLDL) (Sigurdsson et al. 1975). It seems unnecessary to invoke changes in hepatic cholesterol synthesis as an explanation. Reduced cholesterol synthesis in the liver after a shunt could be a consequence of the fall in plasma LDL, because the cholesterol in LDL must presumably be cleared via the liver, and excreted in bile either as cholesterol or as bile acids. It seems likely that the transfer of LDL cholesterol to the liver and its accumulation there might inhibit further synthesis.

Bloom: What happens to the high density lipoprotein (HDL) level?

Star:l: Portal diversion has a general antilipidaemic effect in man (affecting all the lipid moieties). In animals we found that only cholesterol falls after shunt.

Leffert: What is the evidence that the liver doesn't produce LDL directly? 
McIntyre: The studies by the Bethesda group (Eisenberg et al. 1973) suggest that the turnover of the $\beta$-apoprotein of VLDL accounts for all the turnover of LDL apoprotein. Furthermore, if you look for lipoprotein particles in liver by electron microscopy you see VLDL but not LDL particles (Marsh 1971). Some people think that some LDL is produced in the liver, without good evidence.

Starzl: Hepatic cholesterol or LDL synthesis (or both) have been studied in dogs (Starzl et al. 1975), in rats (Edwards et al. 1976; James et al. 1977), in pigs (Chase \& Morris 1976; Carew et al. 1976) and in a human with Type II hyperlipidaemia (Bilheimer et al. 1975). The cholesterol or LDL synthesis was reduced in all these investigations. When both cholesterol and LDL synthesis were measured, as was done for example in Bilheimer's patient, they fell together.

McIntyre: It has been claimed that LDL is secreted directly from the liver in patients homozygous for Type II hypercholesterolaemia (Soutar et al. 1977). The evidence is indirect. If the suggestion is correct we must invoke a special mechanism for LDL production in these patients.

Starzl: You may be correct about a special mechanism, but several of the reports I cited did not question the role of the liver in LDL synthesis. I was not aware that the connection between cholesterol and LDL metabolism was in question in experimental animals or humans.

McIntyre: The work by Goldstein \& Brown (1975) suggests that LDL is removed from plasma by various cells, including fibroblasts, which have specific LDL receptors. If, as in homozygous Type II hypercholesterolaemia, there are no receptors for LDL on the cells, one would expect high cholesterol levels in plasma. This is an excellent explanation for the hypercholesterolaemia and extremely good evidence must be produced in support of another mechanism involving abnormalities of LDL secretion in these patients.

Leffert: Of the hormones we have been talking about, the group in J. W. Porter's laboratory (Ness et al. 1973; Nepokroeff et al. 1974) showed that insulin, glucagon, L-triiodothyronine and hydrocortisone regulate HMG-coA ( $\beta$-hydroxy- $\beta$-methylglutaryl coenzyme $\mathrm{A}$ ) reductase.

D. B. Weinstein and his colleagues (personal communication) have shown that non-growing adult hepatocytes in culture produce VLDL directly where it is secreted into the medium (unpublished studies). If the liver is producing cholesterol via HMG-coA reductase, what is it doing there? VLDL particles contain predominantly triglyceride, not cholesterol. How do you explain the cholesterol composition of extracellular LDL derived from VLDL?

McIntyre: The VLDL apoprotein becomes the apoprotein of LDL; the cholesteryl ester content of LDL could be explained by its transfer, with apo- protein of the $c$ (Goodm: to LDLf process. responsit unsatura:

Why is the liver: because : excreted tripetal $f$ makes it and regu

Star=l: these pait

McIn: think ar.

Star:: : there haevery $F$ except t: vein was these $\mathrm{p} a$ : before 2 state $\mathrm{W}$.. to the c:?

Folkm. lation $s:$ with hy? have pro: are norm ever, as : by intra: : returns ii lipids in:

By $\mathrm{CC}^{-}$: lipid leve bleedin: Perh:- 
the hyperlipidaemia Type II children who had portacaval shunts than in the glycogen storage disease patients who had shunts.

Weinbren: From a pathological viewpoint, there is a characteristic type of atheroma in hyperlipidaemic patients. It is found in the first $4 \mathrm{~cm}$ of the ascending aorta and may involve the coronary ostia. The lesion in the coronary artery in the girl who eventually died was not the usual one. It might have been a superimposed thrombus, far down the coronary artery. The others seemed to wax and wane with treatment by plasmapheresis. Therefore on the angiogram if one finds a lesion along the coronary artery, that may be the one to treat with by-pass, but if it is at the ostium, it may recede.

Starzl: Yes. These lesions in two of our patients were in the ascending aorta and in one there was a big atheroma acting almost like a ball valve, and presumably compromising the coronary ostia. But in these two patients, including one who eventually had a triple coronary artery by-pass, there was also peripheral arterial disease.

In all the early cases of portal diversion for hyperlipidaemia, the patients had homozygous disease. There are also heterozygotes but with high levels of $600-700 \mathrm{mg} / 100 \mathrm{ml}$ cholesterol. One such patient was recently reported from Harvard in which coronary artery by-passes were combined with portacaval shunt with good results (Weglicki et al. 1977). Extension from the homozygous disease to the heterozygous condition may presage a more frontal assault on traditional premature coronary artery disease which involves peripheral vessels.

Weinbren: We have seen heterozygotes who have lesions in the first part of the ascending aorta which may be different from general atheroma in an old patient. But full documentation on this point is not yet available.

Folkman: Why does the glycogen storage disease patient with a very high cholesterol level never develop arterial disease?

McIntyre: The cholesterol is in different particles; it is presumably not predominantly in low density lipoproteins, as it is in Type II hypercholesterolaemia, but rather in VLDL and chylomicrons. The patients whom Dr Starzl is talking about don't have high levels of triglycerides.

Starzl: The relation of the atherosclerosis in hyperlipidaemia to conventional atherosclerotic disease will be interesting to define, particularly if the lesions can be reversed. Small \& Shipley (1974) looked at the question of the factors that would make it possible for atherosclerosis to be cleanly reversed, from a physicochemical point of view. The conclusions were somew hat discouraging. Although reversal would seem to be possible in terms of lipid removal, a lot of residual fibrotic changes cannot be expected to go away. I would therefore tend to be much more aggressive than I was with our child who died of coronary artery complications. If there was a serious cardiovascular complication, I 
in the

ype of

of the

coron-

might

others

on the

he one

inding

2 , and

ts, in-

e was

tients

els of

from

caval

gous

:It on

ssels.

irt of

1 old

high

pre-

mia,

I is

onal

ions

tors

$\mathrm{m} \mathrm{a}$

ing.

$\mathrm{t}$ of

ore

ary

1, I

would combine portal diversion with traditional cardiac surgery approaches.

McIntyre: If people start to do shunts in heterozygotes, we shall soon know all the answers about portal deprivation; they would be excellent people to study!

Starzl: Yes, and clearly they will respond as well as the homozygotes in terms of serum lipid lowering.

\section{References}

AHRENS, E. H., JR (1974) Homozygous hypercholesteraemia and the portacaval shunt: the need for a concerted attack by surgeons and clinical researchers. Lancet 2, 449-451

Beckelbaum, R. J., Lees, R. S., Small, D. M., Hedberg, S. E. \& Grundy, S. M. (1977) Failure of complete bile diversion and oral bile acid therapy in the treatment of homozygous familial hypercholesterolaemia. N. Engl. J. Med. 296, 465-470

Bilheimer, D. W., Goldstein, J. L., Grundy, S. M. \& Brow , M. S. (1975) Reduction in cholesterol and low density lipoprotein synthesis in a patient with homozygous familial hypercholesterolemia. J. Clin. Invest. 56, 1420-1430

Buchwald, H., Moore, R. B. \& Varco, R. L. (1974) Surgical treatment of hyperlipidemia. Circulation 44 (Suppl. 1), 1-37

Carew, T. E., Saik, R. P., Johansen, K. H., Dennis, C. A. \& Steinberg, D. (1976) Low density and high density lipoprotein turnover following portacaval shunt in swine. $J$. Lipid Res. 17, 441-450

Chase, H. P. \& Morris, T. (1976) Cholesterol metabolism following portacaval shunt in the pig. Atherosclerosis 24, 141-148

EisenberG, S., Bilheimer, D. W., Levy, R. I. \& Lindgren, F. T. (1973) On the metabolic conversion of human plasma very low density lipoprotein to low density lipoprotein. Biochim. Biophys. Acta 326, 361

Edwards, K. D. G., Herz, R., Sealey, J. E. \& Bradley, S. E. (1976) Lowering of blood pressure, plasma renin substrate, cholesterol and triglyceride by portacaval anastomosis in rats fed on a $60 \%$ sucrose $/ 5 \%$ lard diet. Clin. Sci. Mol. Med. $51,1455-1465$

Folkman, J., Phillipart, A., Tze, W.-J. \& Crigler, J., JR (1972) Portacaval shunt for glycogen storage disease: value of prolonged intravenous hyperalimentation before surgery. Surgery 72, 306-314

Goldstein, J. L. \& Brown, M. S. (1975) Hyperlipidaemia in coronary heart disease: a biochemical genetic approach. J. Lab. Clin. Med. 85, 15-26

Goodman, D. S. (1965) Cholesterol ester metabolism. Physiol. Rev. 45, 747-839

James, J., Soeters, P. B. \& FisCher, J. E. (1977) in vivo demonstration of impaired cholesterol and fatty acid synthesis following portacaval shunt (PCS). Gastroenterology 72 (no. 5 , part 2), 1075 (abstr.)

Leffert, H., Alexander, N. M., Faloona, G., Rubalcava, B. \& Unger, R. (1975) Specific endocrine and hormonal changes associated with liver regeneration in adult rats. Proc. Natl. Acad. Sci. U.S.A. 72, 4033-4036

Marsh, J. B. (1971) Biosynthesis of plasma lipoproteins, in Plasma Lipoproteins (Smellie, R. M. S., ed.), Academic Press, London

Nepokroeff, C. M., Lakshmanan, M. R., Ness, G. C., Dugan, R. E. \& Porter, J. W. (1974) Regulation of the diurnal rhythm of rat liver $\beta$-hydroxy- $\beta$-methylglutaryl coenzyme A reductase activity by insulin, glucagon, cyclic AMP and hydrocortisone. Arch. Biochern. Biophys. 160, 387-393

Ness, G. C., Dugan, R. E., Lakshmanan, M. R., Nepokroeff, C. M. \& Porter, J. W. (1973) Stimulation of hepatic $\beta$-hydroxy- $\beta$-methylglutaryl coenzyme $A$ reductase activity 
in hypophysectomized rats by L-triiodothyronine. Proc. Natl. Acad. Sci. U.S.A. 70, 3839-3842

Sigurdsson, G., Nicoll, A. \& Lewis, B. (1975) Conversion of very low density lipoprotein to low density lipoprotein. A metabolic study of apolipoprotein B kinetics in human subjects. J. Clin. Invest. 56, 1481

SMAll, D. M. \& Shipley, G. G. (1974) Physical chemical basis of lipid deposition in atherosclerosis. Science (Wash. D.C.) 185, 222-229

Starzl, T. E., Lee, I. Y., Porter, K. A. \& Putnam, C. W: (1975) The influence of portal blood upon lipid metabolism in normal and diabetic dogs and baboons. Surg. Gynecol. Obstet. 140, 381-396

Soutar, A. K., Myant, N. B. \& Thompson, G. R. (1977) Simultaneous measurement of VLDL-apoB and LDL-apoB synthesis in familial hypercholesterolaemia. Abstracts, $X X V$ Annual Colloquium Protides of the Biological Fluids, May 1977

Weglicki, W. B., Ganda, O. P., Soeldner, J. S., Murawski, B. J., Cohn, L. H. \& Couch, N. P. (1977) Portacaval diversion for severe hypercholesterolemia. Arch. Surg. 112, 634-640

\section{Glycog to ther:}

JOHN F. CRIC

Departments of Medical Center Boston, Massai

\begin{abstract}
on the ms glycogenc this disor: results frc of the the night intr overnigh: metabolic glucose $c$. latory by. prevent $\mathrm{t}$ : previousl:
\end{abstract}

In the spring alimentation with oral ad: hormonal ar: brother with diagnosis of $\subseteq$ previously b! analyses. Th and hormona Howell 1972 , evident bioct markedly acc est to note th. 